\title{
Kansei Engineering Analysis of Purple-clay Teapot Based on Online Comment Data
}

\author{
Xinyu ZHANG ${ }^{1}$, Bin QI ${ }^{1 *}$, Yanpu YANG ${ }^{2}$, Xiaoming SUN ${ }^{1}$ \\ 1 Shandong University of Technology, Zibo, China \\ 2 Chang'an University, Xi'an, China
}

*Corresponding Author: Bin QI , Shandong University of Technology, 255049, China; email: billbox0626@163.com

\begin{abstract}
:
Product form has become an important communication medium between designers and consumers. Therefore, the collection and analysis of consumer evaluation of products can provide an important reference index for product form design. In this paper, purpleclay teapot was taken as an example and comments of Tmall consumers were collected through web crawler, and the product image vocabulary was extracted to analyze the needs of users. Using the research method of Kansei Engineering, the semantic space of the modeling and image of purple-clay teapot was established, and the relationship between the modeling elements and the image of purple-clay teapot was searched, which could provide valuable reference for the modeling design of purple-clay teapot.

Keywords: Kansei Engineering; image semantic; purple-clay teapot; crawler; quantitative theory
\end{abstract}

\section{Introduction}

As a unique pottery and clay handicraft in China, purpleclay teapot is a branch with distinct characteristics in Chinese ceramic culture. It combines the artistry of arts and crafts with the practicality of articles for daily use, which is closer to people's daily life. The unique shape of the purpleclay teapot can show its different emotional experience. In this paper, consumers' emotional image of purple-clay teapot was acquired through web crawler to research the relationship between modeling elements and image semantics of purple-clay teapot. When the craftsmen and designers design the purple-clay teapot, certain theoretical guidance can be provided according to the research on consumer demand.

\section{Theoretical Basis and Technical Route}

\subsection{Kansei engineering}

Originated in Japan, Kansei Engineering (KE) is a set of theories and methods to quantify the emotional psychological factors of users, which was put forward in 1970 by Mitsuo Nagamachi ${ }^{[1]}$, a scholar at Hiroshima University in Japan, and Kenichi Yamamoto, former chairman of Mazda automobile group. KE was initially put forward to better understand the needs of consumers and to express the subconscious requirements of consumers on product attributes in a more clear and objective way. It can quantify irrational and difficult to describe emotional and psychological factors into rational expression, and finally establish a set of new product research and development system oriented by consumer demand. Analysis of KE is often used to understand consumers' expectations on product modeling, color, texture, layout, etc., and to explore consumers' feelings and demands for products ${ }^{[2]}$, so as to better guide the design.

\subsection{Data-driven}

Data-driven is a method to acquire, analyze and process massive data in time. Data-driven analysis combined with $\mathrm{KE}$ can enable designers to have many advantages in design analysis [3]. Data-driven method has the following advantages: perceptual words are derived from user's comment data for this kind of products, and the collected perceptual words are highly targeted; the online comment data-oriented perceptual evaluation method is adopted to ensure the authenticity of the comment data; and the crawler program is used to automatically collect data, which makes the data collection efficient and numerical ${ }^{[4]}$. In this paper, the first-hand evaluation data from consumers on purple-clay teapot can be directly obtained through data mining, which was not instructive, and the emotional words 
collected are highly targeted to cases. A large number of online comment data were used for emotional evaluation, which can better ensure the authenticity and reliability of comment data. Moreover, the way of collecting data through web crawler is characterized by high efficiency, strong real-time performance and large amount of data collection.

\subsection{Quantification-I theory}

Quantification-I theory ${ }^{[5,6,7]}$ is a method to establish the relationship between variables by using mathematical model. For the field of Kansei Engineering, by establishing a mathematical model based on Quantification-I theory, qualitative problems can be quantitatively analyzed, which can more intuitively and clearly analyze the relationship between the emotional image of consumers and the form elements of modeling design ${ }^{[8,9,10]}$, and apply the analysis results to product design innovation.

In this paper, form elements of purple-clay teapot were analyzed by combining KE, data-driven and quantitative theories, and the research technical route is shown in Figure 1.

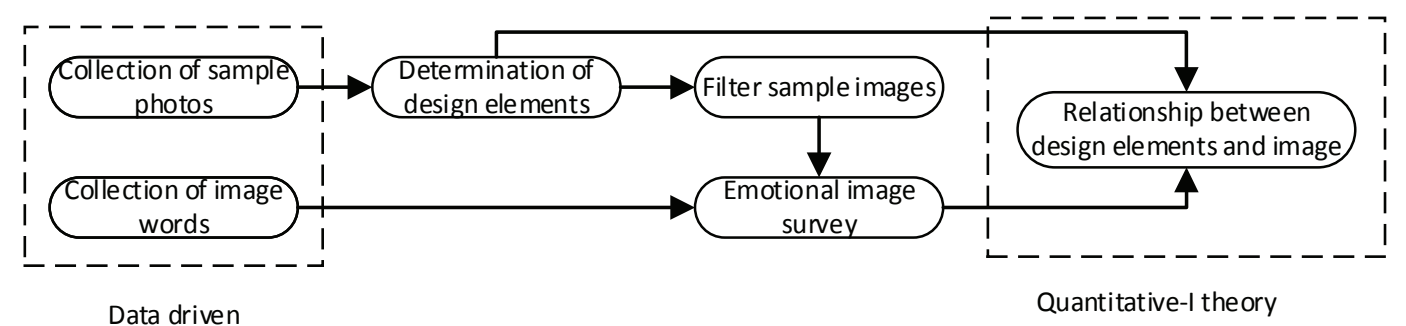

Figure 1. Research Technical Route

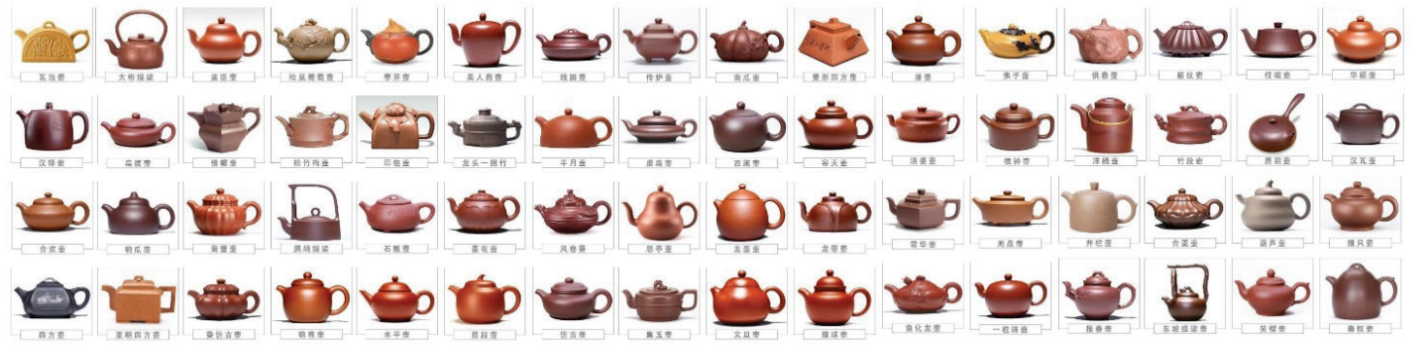

Figure 2. 64 Classic purple-clay teapot

Table 1. Feature Coding Matrix for Design of Morphological Elements

\begin{tabular}{|c|c|c|c|c|c|c|c|c|}
\hline & Category Ci1 & Category Ci2 & Category Ci3 & Category Ci4 & Category Ci5 & Category Ci6 & Category Ci7 & Category Ci8 \\
\hline \multirow{2}{*}{$\begin{array}{l}\text { Kettle body } \\
\text { modelling element } \\
\text { C1j }\end{array}$} & & & & & & & & \\
\hline & Spherical C11 & $\begin{array}{c}\text { Elliptical } \\
\text { (vertical) }\end{array}$ & $\begin{array}{c}\text { Elliptic } \\
\text { (transverse) C13 }\end{array}$ & Cylindrical C14 & Cylindrical C15 & Inverted table $\mathrm{C} 16$ & Square platform C17 & Square C18 \\
\hline \multirow{2}{*}{$\begin{array}{l}\text { Kettle spit } \\
\text { modelling element } \\
\quad C 2 j\end{array}$} & & & & & & & & \\
\hline & Curved spit 1, C21 & Curved spit 2, C22 & Curved spit $3, \mathrm{C} 23$ & Straight spit, C24 & $\begin{array}{l}\text { Short straight spit } \\
\text { C225 }\end{array}$ & & & \\
\hline \multirow[t]{2}{*}{$\begin{array}{l}\text { Kettle handle } \\
\text { modell ling element } \\
\text { C3j }\end{array}$} & & & & & & $l_{1}$ & & \\
\hline & $\begin{array}{c}\text { Arc front ear handle } \\
\text { C31 }\end{array}$ & $\begin{array}{l}\text { Arc inverted ear } \\
\text { handle C32 }\end{array}$ & $\begin{array}{l}\text { Handle with straight } \\
\text { line C } 33\end{array}$ & Round ear handle C34 & Handle C34 & \begin{tabular}{|c|} 
Lifting beam handle \\
C 36
\end{tabular} & $\begin{array}{c}\text { Flying kettle handle } \\
\text { C37 }\end{array}$ & \\
\hline \multirow{2}{*}{$\begin{array}{l}\text { Kettle cover } \\
\text { modell ing element } \\
\quad \mathrm{C} 4 \mathrm{j}\end{array}$} & & & & & & & & \\
\hline & Nested cover pot C41 & $\begin{array}{l}\text { Pressing cover pot } \\
\mathrm{C} 42\end{array}$ & \begin{tabular}{|c|} 
Cutting cover pot \\
$\mathrm{C} 43$
\end{tabular} & & & & & \\
\hline \multirow{2}{*}{$\begin{array}{l}\text { Kettle button } \\
\text { modell ling element } \\
\text { C5j }\end{array}$} & & & & & & & & \\
\hline & Spherical C51 & Cylindrical C52 & Bridge shape $\mathrm{C}^{2} 3$ & Ellipse C54 & \begin{tabular}{|c|c|} 
Transverse ell ipse \\
$\mathrm{C55}$
\end{tabular} & & & \\
\hline \multirow{2}{*}{$\begin{array}{l}\text { Pott-foot modeling } \\
\text { element } \mathrm{C} 6 \mathrm{j}\end{array}$} & & & प & & & & & \\
\hline & Bottomless C61 & Add bottom $\mathrm{C} 62$ & Nail foot $\mathrm{C} 63$ & & & & & \\
\hline
\end{tabular}




\section{Study Process}

\subsection{Specimen collection}

In this paper, the purple-clay teapot is taken as the research object. Through literature review[11], field visits and other ways to investigate the classic shapes of the purple-clay teapot, about 64 kinds of the classic shapes of the purple-clay teapot have been obtained. The form of 64 kinds of classic purple-clay teapots was analyzed. Tmall purple purpleclay teapot were crawled with crawler tools and the front view of the classic purple-clay teapot was obtained through screening, which is convenient for product evaluation and feature extraction and induction in the later stage. In order to better exclude the influence of other factors, the background of the collected pictures of 64 kinds of classic purple-clay teapot was unified, as shown in Figure 2.

\subsection{Analysis and extraction of modeling elements}

After determining the classic modeling samples, 64 kinds of purple-clay teapot were decomposed. Focus group method was used to extract the modeling design elements of purple-clay teapot and subdivide its design categories. It is known that the purple-clay teapot can be divided into six morphological design elements, such as lid, body, spout, handle, knob and foot, and its morphological design elements can be subdivided into 30 design categories. The shape and form design elements of purple-clay teapot were digitally coded to ensure that each shape and form element and design category was significantly differentiated. Finally, the shape and form design feature coding matrix of purpleclay teapot was formed as shown in Table 1.

\subsection{Sample selection}

64 pictures of purple-clay teapot were coded. The formula takes $\mathrm{X}_{\mathrm{n}}$ to represent the sample and $\mathrm{C}_{\mathrm{ij}}$ to represent the design features, then the combination of the characteristic elements of the purple-clay teapot is:

$$
\begin{gathered}
X_{1}=\left\{C_{15}, C_{21}, C_{32}, C_{41}, C_{52}, C_{61}\right\} \\
X_{2}=\left\{C_{12}, C_{22}, C_{34}, C_{42}, C_{53}, C_{62}\right\} \\
\ldots \ldots \\
X_{m}=\left\{\ldots, \ldots, \ldots, C_{i j}, \ldots, \ldots\right\} \\
\ldots \ldots \\
X_{64}=\left\{C_{14}, C_{25}, C_{30}, C_{43}, C_{51}, C_{61}\right\}
\end{gathered}
$$

In order to better screen out the appropriate samples, through cluster analysis, samples that can meet all the characteristics of 31 modeling elements were selected from 64 classical purple sand pot models. A total of 12 samples were screened out. The modeling elements of these samples include all types of purple-clay teapot. Twelve samples were processed with gray level to exclude the influence of color on the perceptual image, as shown in Figure 3.

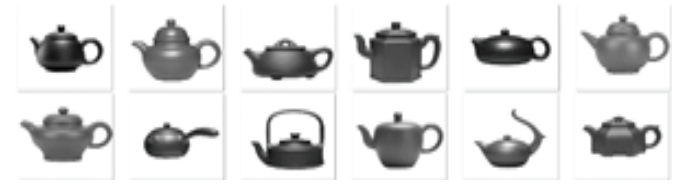

Figure 3. Screened samples

\subsection{Collection of emotional image words}

Tmall platform is a comprehensive shopping website ${ }^{[12]}$, and its sales categories are complete, most of which are in the form of flagship stores. Therefore, we selected the review data of purple-clay teapot in Tmall e-commerce platform as the research object, and grabbed the sales data of June 7, 2019 through Python program, on which 79,377 related products of purple-clay teapot were sold on Tmall platform. In order to better capture useful data, we only captured 18035 review data from the stores with the highest sales volume and review volume. The stores with the highest sales volume and review volume can reflect that these stores are more in line with users' needs.

\subsection{Comment data preprocessing}

Data directly obtained by web crawler usually have a lot of noise data, so it is necessary to preprocess the data. Due to the influence of word diversity, wrong words and network buzzwords, this paper adopts stuttering participle for word segmentation and part of speech tagging.

To extract adjectives, that is, after tagging the collected comments with part of speech, the adjectives described in the comments for purple clay pot are selected.

Inductive similar adjectives. Summarize the collected adjectives and delete those who do not conform to the actual situation, such as "cheap" and other adjectives that are not suitable for evaluating the shape. Similar adjectives such as "beautiful", "good-looking" and "beautiful" are classified by the same category.

Get image vocabulary. Make descending order of the inducted adjectives and select the top 30 adjectives. The purple-clay teapot was evaluated through focus groups using selected adjectives. The focus group consists of 20 design students (male 11, female 9). Each member is limited to 10 words from 30 words, which can be used to evaluate purple sand teapots. Finally, the top 5 descriptive words were summarized, as shown in Table 2. And the negative words are summarized, cute - serious, soft - masculine, boring - fun, light - bulky, fragility - firmness.

Table 2. Frequency table of image vocabulary pairs

\begin{tabular}{cc}
\hline Pair of image words & Number of times used \\
\hline Cute - serious & 18 \\
Soft - masculine & 17 \\
Boring - fun & 17 \\
Light - bulky & 15 \\
Fragility - firmness & 13 \\
\hline
\end{tabular}

\subsection{Establish the space of image meaning}

Based on the selected samples and image vocabulary groups, the questionnaire was compiled to establish an image semantic space for the description of morphological elements of purple-clay teapot. Using SD method and combining 7-point Likert Scale to grade the shape of purple-clay teapot, a semantic axis of 1 7 was formed. 
A total of 273 questionnaires were distributed, 269 were collected, and 260 were valid statistical data. The analysis of the results is shown in Table 3.

The statistical results are exported to SPSS statistical software for analysis, and the standard deviation of image word pairs is obtained, as shown in Table 4. As shown in
Figure 4, the semantic axes of the images of samples were drawn. From the descriptive statistical analysis and the combination of the semantic axes of the samples, it can be concluded that the image vocabulary group of "masculinity -- softness" can better analyze the semantic space of the samples.

Table 3. Mean value of image evaluation

\begin{tabular}{|c|c|c|c|c|c|c|c|c|c|c|c|}
\hline Sample & Cute - serious & Soft - masculine & Boring - fun & Lightweight - bulky & Fragility - firmness & Sample & Cute - serious & Soft - masculine & Boring - fun & Lightweight - bulky & Fragility - firmness \\
\hline & -0.73 & -1.54 & -0.19 & 0.23 & 1.03 & & 0.27 & 0.15 & -0.09 & 0.49 & -0.08 \\
\hline & -0.63 & -0.67 & -0.41 & 0.95 & 0.79 & & -2.16 & -1.83 & 1. 49 & -0.79 & -0.39 \\
\hline & -0.19 & -0.32 & 1. 03 & 0.47 & 0.51 & & 1. 46 & 1. 36 & 0.45 & 0.45 & 0.09 \\
\hline & 2. 25 & 2. 46 & -1.02 & 1.65 & 1. 84 & & -0.59 & -1.21 & -0.55 & 0.41 & 0.13 \\
\hline & -1.26 & -2.02 & 1. 21 & -0.86 & 0.09 & & -1.31 & -1.23 & 1. 49 & -0.59 & -0.81 \\
\hline & 0.01 & -0.26 & -0.85 & 0.39 & 0.65 & & 1. 79 & 1.76 & -0.19 & 1. 43 & 1. 58 \\
\hline
\end{tabular}

Table 4. Statistical results

\begin{tabular}{|c|c|c|c|c|c|c|c|c|c|c|c|c|c|}
\hline \multicolumn{10}{|c|}{ Descriptive Statistics } \\
\hline & $\mathrm{N}$ & Range & Minimum & Maximum & Sum & \multicolumn{2}{|c|}{ Mean } & \multicolumn{1}{|c|}{ Std. Deviation } & \multicolumn{2}{|c|}{ Variance } & \multicolumn{2}{|c|}{ Skewness } & \multicolumn{2}{|c|}{ Kurtosis } \\
\hline & Statistic & Statistic & Statistic & Statistic & Statistic & Statistic & Std. Error & Statistic & Statistic & Statistic & Std. Error & Statistic & Std. Error \\
\hline Cute - serious & 12 & 4.41 & -2.16 & 2.25 & -1.09 & -0.090833333 & 0.385882417 & 1.336735905 & 1.786862879 & 0.477065707 & 0.637302005 & -0.526223831 & 1.232246474 \\
\hline Soft - masculine & 12 & 4.48 & -2.02 & 2.46 & -3.35 & -0.279166667 & 0.421782757 & 1.461098331 & 2.134808333 & 0.726727726 & 0.637302005 & -0.578306962 & 1.232246474 \\
\hline Boring - fun & 12 & 2.51 & -1.02 & 1.49 & 2.37 & 0.1975 & 0.261311161 & 0.905208414 & 0.819402273 & 0.32552934 & 0.637302005 & -1.447423632 & 1.232246474 \\
\hline Lightweight - bulky & 12 & 2.51 & -0.86 & 1.65 & 4.23 & 0.3525 & 0.229082905 & 0.793566461 & 0.629747727 & -0.100176 & 0.637302005 & -0.471337322 & 1.232246474 \\
\hline Fragility - firmness & 12 & 2.65 & -0.81 & 1.84 & 5.43 & 0.4525 & 0.22428717 & 0.77695355 & 0.603656818 & 0.338034787 & 0.637302005 & -0.306634471 & 1.232246474 \\
\hline
\end{tabular}
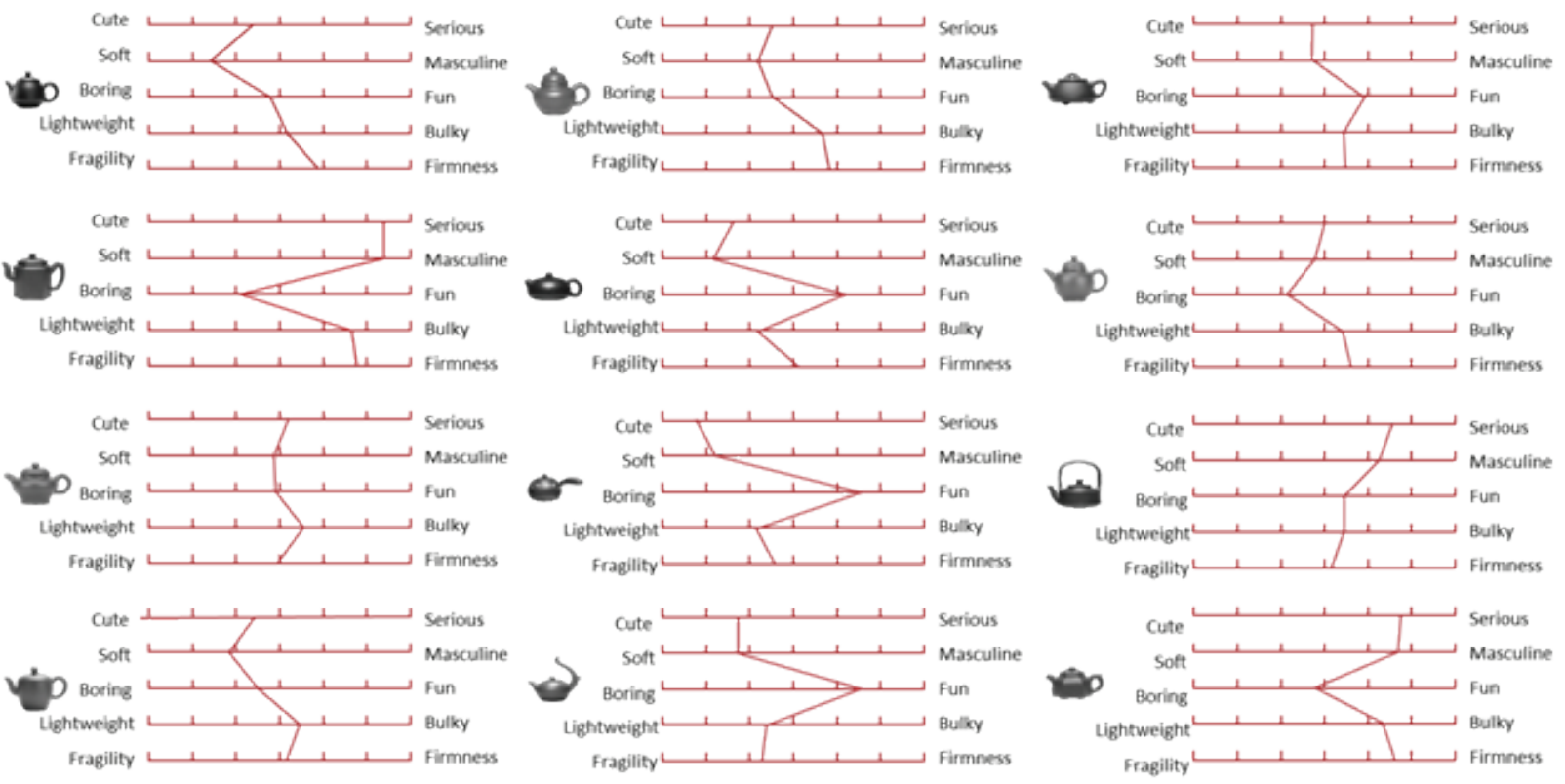

Figure 4. semantic axis of image 
3.7. Construction of a theoretical model of quantification

After the statistical analysis of image words, the relationship between the modeling design elements and image words is described quantitatively by constructing a quantitative theoretical model. Here, the modeling and morphological elements of purple-clay teapot are taken as independent variables, and its perceptual image vocabulary evaluation value is taken as dependent variables, and the objective analysis is conducted by means of multiple regression. The formula is as follows :

$$
Y_{m}=\sum_{i=1}^{n} \sum_{j=1}^{\eta} \delta_{m}(i, j) b_{i j}+\varepsilon_{m}
$$

Where

$$
\begin{gathered}
\delta_{\mathrm{m}}(\mathrm{i}, \mathrm{j})=\left\{\begin{array}{c}
1 \text { Insamplem, thequalitativefactorforitemIiscategoryj } \\
0
\end{array}\right. \\
\quad \text { Noorother } \\
\mathrm{Y}_{\text {Soft-Masculine }}=\left\{\begin{array}{c}
\mathrm{b}_{11} \delta_{\mathrm{m}}(1,1) \\
\vdots \\
\mathrm{b}_{18} \delta_{\mathrm{m}}(1,8)
\end{array}+\left\{\begin{array}{c}
\mathrm{b}_{21} \delta_{\mathrm{m}}(2,1) \\
\vdots \\
\mathrm{b}_{25} \delta_{\mathrm{m}}(2,5)
\end{array}+\left\{\begin{array}{c}
\mathrm{b}_{31} \delta_{\mathrm{m}}(3,1) \\
\vdots \\
\mathrm{b}_{37} \delta_{\mathrm{m}}(3,7)
\end{array}\right.\right.\right. \\
+\left\{\begin{array}{c}
\mathrm{b}_{41} \delta_{\mathrm{m}}(4,1) \\
\vdots \\
\mathrm{b}_{43} \delta_{\mathrm{m}}(4,3)
\end{array}+\left\{\begin{array}{c}
\mathrm{b}_{51} \delta_{\mathrm{m}}(5,1) \\
\vdots \\
\mathrm{b}_{54} \delta_{\mathrm{m}}(5,4)
\end{array}+\left\{\begin{array}{c}
\mathrm{b}_{61} \delta_{\mathrm{m}}(6,1) \\
\vdots \\
\mathrm{b}_{63} \delta_{\mathrm{m}}(6,3)
\end{array}+\varepsilon_{\mathrm{m}}\right.\right.\right.
\end{gathered}
$$

\section{Experimental Results and Analysis}

Combined with the Quantification-I theory, the analysis of the Masculine - soft quantitative model is carried out, and the results are shown in Table 5 .

According to the analysis of quantification-i theory ${ }^{[13]}$, the order of partial correlation coefficient is: Pot handle $(0.553)>\operatorname{lid}(0.311)>$ foot $(0.23)>$ knob $(0.125)$. This shows that in the perceptual evaluation of purple-clay teapot, the body has the greatest influence on "masculinity - soft", the spout and handle are the second, while the foot and knob have the least influence on "masculinity soft". In a word, in the process of analyzing the scores of various morphological elements in the purple-clay teapot, the larger the positive value is, the greater the influence of the morphological elements on the image of "softness"; on the contrary, the lower the score is, the more masculine the image is.

Similarly, this method can quantitatively analyze the correspondence between other modeling elements and other perceptual image vocabulary groups.

\section{Conclusion}

With the development of network technology, more and more consumers carry out shopping through network. By collecting a large amount of comment data from e-commerce platforms for analysis, it can better provide data sources for design. By crawling online comment data, a large amount of data can be obtained and the part of speech and word frequency can be quickly analyzed, which is more efficient than the traditional collection of emotional words through books, advertisements, newspapers and other means. A large number of samples can be obtained by crawling the e-commerce platform through the network crawler. The samples of the e-commerce platform are directly oriented to consumers, which is of great reference significance. In this

\begin{tabular}{|c|c|c|c|}
\hline $\begin{array}{l}\text { Design } \\
\text { elements }\end{array}$ & Form elements & $\begin{array}{c}\text { Category } \\
\text { score }\end{array}$ & $\begin{array}{c}\text { Partial } \\
\text { correlation } \\
\text { coefficient }\end{array}$ \\
\hline \multirow{8}{*}{$\begin{array}{l}\text { Kettle body } \\
\text { modelling } \\
\text { element }\end{array}$} & Spherical C11 & 0.593 & \multirow{8}{*}{0.945} \\
\hline & Elliptical (vertical) C12 & 0.091 & \\
\hline & Elliptic (transverse) C13 & 0.213 & \\
\hline & Cylindrical C14 & 0.015 & \\
\hline & Cylindrical C15 & -0.161 & \\
\hline & Inverted table $\mathrm{C} 16$ & -0.015 & \\
\hline & Square platform $\mathrm{C} 17$ & -0.203 & \\
\hline & Square $\mathrm{C} 18$ & -0.352 & \\
\hline \multirow{5}{*}{$\begin{array}{l}\text { Kettle spit } \\
\text { modelling } \\
\text { element }\end{array}$} & Curved spit 1, C21 & 0.121 & \multirow{5}{*}{0.566} \\
\hline & Curved spit 2, C22 & 0.201 & \\
\hline & Curved spit 3, C23 & 0.462 & \\
\hline & Straight spit, C24 & -0.104 & \\
\hline & Short straight spit, C25 & 0.321 & \\
\hline \multirow{7}{*}{$\begin{array}{l}\text { Kettle handle } \\
\text { modelling } \\
\text { element }\end{array}$} & Arc front ear handle C31 & 0.201 & \multirow{7}{*}{0.556} \\
\hline & Arc inverted ear handle C32 & 0.241 & \\
\hline & Handle with straight line C33 & -0.218 & \\
\hline & Round ear handle C34 & 0.125 & \\
\hline & Handle C34 & -0.103 & \\
\hline & Lifting beam handle $\mathrm{C} 36$ & -0.315 & \\
\hline & Flying kettle handle C37 & 0.121 & \\
\hline \multirow{3}{*}{$\begin{array}{l}\text { Kettle cover } \\
\text { modelling } \\
\text { element }\end{array}$} & Nested cover pot C41 & 0.021 & \multirow[t]{3}{*}{0.312} \\
\hline & Pressing cover pot C42 & 0.102 & \\
\hline & Cutting cover pot $\mathrm{C} 43$ & 0.333 & \\
\hline \multirow{5}{*}{$\begin{array}{l}\text { Kettle knob } \\
\text { modelling } \\
\text { element }\end{array}$} & Spherical C51 & 0.012 & \multirow{5}{*}{0.121} \\
\hline & Cylindrical C52 & 0.025 & \\
\hline & Bridge shape C53 & -0.012 & \\
\hline & E11ipse C54 & 0.109 & \\
\hline & Transverse ellipse C55 & 0.033 & \\
\hline \multirow{3}{*}{$\begin{array}{l}\text { Kettle foot } \\
\text { modelling } \\
\text { element }\end{array}$} & Bottomless C61 & 0.319 & \multirow[t]{3}{*}{0.21} \\
\hline & Add bottom $\mathrm{C} 62$ & 0.214 & \\
\hline & Nail foot C63 & 0.091 & \\
\hline \multicolumn{3}{|c|}{ Constant term } & 2.49 \\
\hline
\end{tabular}
paper, the purple-clay teapot was analyzed by combining Kansei Engineering and Quantification-I theory, which provides a new idea for product design research.

Table 5. Quantification-I theory analysis results

\section{References}

[1] Mitsuo Nagamachi, Kansei engineering as a powerful consumer-oriented technology for product development. APPLIED ERGONOMICS. 33, 3(2002)

[2] Yan Pu Yang, Deng Kai Chen, Rong Gu, Yu Feng Gu and Sui Huai Yu, Consumers' Kansei Needs Clustering Method for Product Emotional Design Based on Numerical Design Structure Matrix and Genetic Algorithms. Computational Intelligence \& Neuroscience. 2016, (2016)

[3] Alex Boulton, Testing the limits of data-driven learning: Language proficiency and training. ReCALL. 21, 1(2009)

[4] L. I. Shaobo, Huafeng Quan, H. U. Jianjun, W. U. Yongming and Ansi Zhang, Perceptual evaluation method of 
products based on online reviews data driven. Computer Integrated Manufacturing Systems. (2018)

[5] Marzieh Berenjkoub, Rodolfo Ostilla Monico, Robert S. Laramee and Guoning Chen, Visual Analysis of Spatiatemporal Relations of Pairwise Attributes in Unsteady Flow. (2019)

[6] Jin Wang, L. U. Guo-Dong and Yun Long Zhang, Quantification-I theory based IGA and its application. Journal of Zhejiang University. (2013)

[7] S. U. Ke and Shou Qian Sun, Product material image decision-making support model based on GEP. Computer Integrated Manufacturing Systems. 18, 2(2012)

[8] B. Qi, S. Yu and W. He, Product cognitive style based on kansei engineering and visual track experiments. Journal of Applied Sciences. 13, 12(2013)

[9] ZHANG Yufei BIAN Ze LUO Shijian, Status and Progress of Product Shape Bionic Design. Journal of Mechanical Engineering. 54, 21(2018)

[10] Yan Pu Yang, A Method for Consensus Reaching in Product Kansei Evaluation Using Advanced Particle Swarm Optimization. Computational Intelligence and Neuroscience,2017,(2017-02-12). 2017, 2(2017)

[11] Joyita Mallik, Ashok Samal and Scott L. Gardner, A content based image retrieval system for a biological specimen collection. Computer Vision \& Image Understanding. 114, 7(2010)

[12] Yan-pu Yang and Xing Tian, Combining users'cognition noise with interactive genetic algorithms and trapezoidal fuzzy numbers for product color design. Computational Intelligence and Neuroscience. 2019, (2019) 